\title{
Comparison Study of Pulsing and Continuous Flow for Improving Effluent Water Quality and Plant Growth of a Constructed Wetland to Treat Domestic Wastewater
}

\author{
S. Sasikala, N. Tanaka ${ }^{1}$, K.B.S. N. Jinadasa ${ }^{2}$ and M.I.M. Mowjood ${ }^{3}$ \\ Department of Agricultural Engineering \\ Faculty of Agriculture \\ University of Peradeniya, Sri Lanka
}

\begin{abstract}
A wetland used for wastewater treatment should be incorporated with oxygen. One method to improve oxygen concentration in wetland is flow modification. In this study the effect of pulsed sewage water feed on treatment efficiency of free-surface-flow constructed wetlands was studied. This research was conducted in two phases from January to June and June to September in 2006. Two wetland units (L1 and L2) were planted with Scirpus grossus; $L 1$ received a continuous wastewater feed (CF) and L2 a pulsed feed (PF; five days of feed followed by two days of no feed). The removal of biological oxygen demand $\left(B O D_{5}\right)$, ammonium nitrogen $\left(\mathrm{NH}_{4}-\mathrm{N}\right)$, and nitrate nitrogen $\left(\mathrm{NO}_{3}-\mathrm{N}\right)$ were analysed for effluent, and total Kjeldahl nitrogen (TKN) and total phosphorous (TP) in the substrate of both units were compared. Plant growth was monitored continuously for both systems. BOD removal was increased by $14 \%$ by the pulsing application compared to the CF application. The average removal rate of $\mathrm{NO}_{3}-\mathrm{N}$ was $36 \%$ and $45 \%$ in $\mathrm{CF}$ and $\mathrm{PF}$ respectively and the differences were statistically significant. The average removal of $\mathrm{NH}_{4}-\mathrm{N}$ was $27.5 \%$ and $24.0 \%$ in $C F$ and $P F$, which were not significantly different. The TKN near the outlet was $\sim 5$ mg per $100 \mathrm{~g}$ soil in both units. However, TP was higher ( 22 mg per $100 \mathrm{~g}$ soil) at the outlet of the PF unit compared to the CF unit $(\sim 12 \mathrm{mg}$ per $100 \mathrm{~g}$ soil). The maximum plant height was $220 \mathrm{~cm}$ in both systems, and no significant difference was observed. In contrast, the PF unit showed a significant reduction in shoot density and biomass production of $\underline{S}$. grossus compared to the $C F$ unit. The results of this study indicate that the pulse feeding strategy improved the removal of $\mathrm{BOD}_{5}$ and reduced the above ground biomass production compared to the continuous feeding system. However, no clear improvement in ammonium removal was observed in the PF system in comparison to previous studies.
\end{abstract}

\section{INTRODUCTION}

The potential of Constructed Wetlands (CWs) as a secondary treatment for domestic wastewater was found to be significant (Headley et al., 2005). Human waste can have a significant level of ammonium nitrogen $\left(\mathrm{NH}_{4}-\mathrm{N}\right)$ and organic $\mathrm{N}$ (Huang et al., 2000). Unsuitable conditions for the removal of ammonium nitrogen can seriously limit the treatment performance of a wetland system (Clarke et al., 2002). The biochemical processes require the establishment of oxygen-enriched zones (Garcia et al., 2005; Wiessner et al.,

\footnotetext{
1 Graduate School of Science and Engineering, Saitama University, Japan

2 Department of Civil Engineering, Faculty of Engineering, University of Peradeniya, Sri Lanka

3 Department of Agricultural Engineering, Faculty of Agriculture, University of Peradeniya, Sri Lanka
} 
2005) inside the media of the wetland. Kadlec et al., (2000) reported that the treatment efficiencies of CWs depend mainly on the oxidation-reduction conditions of the substrate. Operation mode is one of the main parameters that can be easily modified to improve the oxidation state of the wastewater and wetland soil. Generally, a batch operation system improves aeration of the substrate and therefore, performs better than a continuous operation system.

The oxygen concentration present in CWs is influenced by many factors, such as the organic load, mode of operation (batch, continuous, or pulse), type and development of macrophytes and water depth (Kadlec and Knight, 1996; Garcia et al., 2004). Among these factors, the operation mode is one of the main parameters that can be modified to improve the oxidation state of the wastewater and wetland soil, thereby improving the removal of wastewater nitrogen and oxygen-demanding substances. Several studies have been conducted to evaluate the effects of the mode of operation on the removal efficiency of CWs.

Ammonium nitrogen is one of the principle forms of nitrogen in human waste and due to its role in water quality degradation, reducing the ammonium nitrogen concentration is an important issue. Unsuitable conditions for the removal of ammonium nitrogen can seriously limit the treatment performance of a wetland system. The addition of dissolved oxygen to wastewater can make the environment more aerobic and thereby enhance the removal activity. Several previous studies have revealed that ammonium removal in wetlands could be enhanced by batch systems and water-level fluctuations (Stein et al., 2003; Tanner et al., 1999) where supplemental dissolving of oxygen was noted during the water-level fluctuations.

Wetland plants can enhance $\mathrm{NH}_{4}-\mathrm{N}$ removal, although their lower root zone oxygen limits the rate of nitrification. The aboveground organs of macrophytes contribute to the oxidation of pulse-fed wetland systems (Osorio and Garcia, 2007). Macrophytes also cause water-level fluctuations by increasing the evapotranspiration during pulsed-flow application (Osorio and Garcia, 2007). However, the effect of a pulsing feed on water quality improvement and plant growth in constructed wetlands has not been well documented.

Very few studies are available on free water surface wetlands, regarding this context in tropical regions. Therefore, this study investigated and compared two hydraulic regimes, referred to as pulsing feed (PF) and continuous feed (CF) of wastewater, in constructed wetlands. The objectives of the present investigation were to evaluate the effects of the hydraulic regime on 1) efficiency of domestic wastewater contaminant removal and 2) production of aboveground plant biomass of plants.

\section{MATERIALS AND METHODS}

\section{Constructed wetland system}

A constructed wetland was built to treat wastewater from a student dormitory at the University of Peradeniya, Sri Lanka $\left(7^{\circ} 15^{\prime} \mathrm{N} 80^{\circ} 35^{\prime} \mathrm{E}\right)$. This system was designed to function as a surface-flow wetland. This system consisted of two units named L1 and L2. The length, width and depth of the units were $25 \mathrm{~m}, 1.0 \mathrm{~m}$ and $0.6 \mathrm{~m}$, respectively. A gravel-based medium (depth $0.5 \mathrm{~m}$ ) was used from top to bottom and a soil layer (depth $0.1 \mathrm{~m}$ ) supported the vegetation. S. grossus L (Cyperaceae) was planted at the initial shoot density of 4 shoots $\mathrm{m}^{-2}$. The inlet hydraulic retention time (HRT) was around 24 hours. 


\section{Planting}

Planting of S. grossus L. was done in early January 2006 and the wastewater feed was started soon after planting. Two quadrates of $1 \mathrm{~m}^{2}$ each were placed at $8 \mathrm{~m}$ (near the inlet) and at 16 $\mathrm{m}$ (near the outlet) from the inlet. The quadrate locations were used to calculate the average growth variations of $S$. grossus along the channel.

\section{Plant sampling}

Non-destructive measurements of plant growth (shoot height and shoot density) were taken at fortnight intervals within these two quadrates. For destructive analysis, plants were harvested after 6 months and their biomasses were measured. Harvesting was done twice, at 6 and 10 months after planting, after the formation of inflorescences and plant growth saturation.

\section{System hydraulics}

Wastewater was applied to one unit as CF and to the other as PF. During the PF, wastewater was applied continuously for 5 days and stopped for 2 days. The average flow rate was maintained around $8 \mathrm{~m}^{3}$ per day for the $\mathrm{CF}$ and $11.2 \mathrm{~m}^{3}$ per day for the $\mathrm{PF}$ to equalize the total volume of wastewater treated per week $\left(56 \mathrm{~m}^{3}\right)$.

\section{Water and soil sampling}

Water samples were taken at monthly intervals from January to September 2006. Water samples were collected from the inlet and outlet into sterilized sampling bottles. Water quality parameters such as $\mathrm{BOD}_{5}, \mathrm{NH}_{4}-\mathrm{N}$ and $\mathrm{NO}_{3}-\mathrm{N}$ were measured according to the standard methods (APHA et al., 1998). The soil nitrogen concentration was determined by using the total Kjeldahl method. Total phosphorous was determined by the ascorbic acid method. All statistical analyses ( $t$-test) were performed by using Sigma Stat 3.11 (Systat Software Inc. 2004). P < 0.001 was considered as statistically significant.

\section{RESULTS AND DISCUSSION}

\section{Water quality improvement in wetland systems}

\section{BOD $_{5}$ removal}

Table 1 shows the removal rates of $\mathrm{BOD}_{5}, \mathrm{NO}_{3}-\mathrm{N}$ and $\mathrm{NH}_{4}-\mathrm{N}$ in Phase I (initial development stage from planting to harvesting: January-June, 2006) and Phase II (re-growth stage after harvesting: June-September, 2006). It was noted that $\mathrm{BOD}_{5}$ removal was lower and fluctuated during Phase I. However, when the plants had grown for three months (Phase II), the $\mathrm{BOD}_{5}$ removal was higher and more stable.

$\mathrm{BOD}_{5}$ removal rates were higher in the PF system than that in the CF system in both phases. The $\mathrm{BOD}_{5}$ removal rates in the effluent of the PF unit were around $45 \%$ (Table 1) in Phase I and $53 \%$ in Phase II, whereas they were $31 \%$ and $39 \%$, respectively in the CF system.

It can be assumed that the development of microbial biomass and establishment of plant rhizosphere and system acclimatization occurred during Phase I. Subsequently, the system was well established and showed higher $\mathrm{BOD}_{5}$ removal during Phase II than during Phase I. 
The $\mathrm{BOD}_{5}$ of domestic wastewater tends to be dominated by readily biodegradable organic carbon with a $\mathrm{C}: \mathrm{N}: \mathrm{P}$ ratio that is amenable to biological decomposition (Merz, 2000). Treatment wetlands remove wastewater $\mathrm{BOD}_{5}$ through biochemical and physical decomposition of organic compounds. The decomposition pathway by which wetland carbon loads are processed is determined by a balance between the carbon load and the supply of oxygen (Merz, 2000). Our PF unit had no water application for 2 days, followed by 5 days of continuous water application. This two-day resting period might have improved aeration of the substrate close to the surface. It also had improved the balance between the carbon load and oxygen supply. This two-day pulsing flow may be the reason for the significantly higher $\mathrm{BOD}_{5}$ removal rate of the $\mathrm{PF}$ unit $(\mathrm{P}<0.001)$. In free-water surface wetlands, the microbes on media surfaces get more oxygen from the atmosphere by diffusion than from the subsurface flow wetland. This oxygen participates in the removal of the soluble carbon compounds in the wastewater (Kadlec, 1995). Therefore, free-water surface wetlands are efficient users of external carbon sources, as revealed by higher $\mathrm{BOD}_{5}$ removal.

\section{Nitrogen removal}

The average concentrations of ammonium in the influent were $17.8 \pm 10.2 \mathrm{mg} \mathrm{N} \mathrm{L}^{-1}$ and 9.9 $\pm 4.0 \mathrm{mg} \mathrm{N} \mathrm{L}^{-1}$ for Phase I and Phase II, respectively (Table 1). Ammonia volatilization depends on environmental factors such as solar energy, temperature and wind speed (Pedrazzini and Tarsitano, 1986). Phases I and II were conducted in different seasons and under different environmental conditions. Ammonia removal might also have been affected by the influent ammonium concentrations during Phases I and II. The average effluent concentrations in Phase I were 14.8 \pm 9.2 and 14.6 $\pm 7.2 \mathrm{mg} \mathrm{N} \mathrm{L}^{-1}$ in the $\mathrm{CF}$ and PF systems, respectively. During the Phase II, the respective effluent concentrations were $7.0 \pm 3.2 \mathrm{mg} \mathrm{N}$ $\mathrm{L}^{-1}$ and $6.9 \pm 3.6 \mathrm{mg} \mathrm{N} \mathrm{L}^{-1}$ for the $\mathrm{CF}$ and PF systems, respectively. During Phase II, the removal efficiency increased to $29-30 \%$ compared to that in Phase I, which was 16-18\%.

Table 1. Average removal of biological oxygen demand $\left(\mathrm{BOD}_{5}\right)$, nitrate-nitrogen $\left(\mathrm{NO}_{3}-\mathrm{N}\right)$ and ammonium-nitrogen $\left(\mathrm{NH}_{4}-\mathrm{N}\right)$ in first and second phases

\begin{tabular}{|c|c|c|c|}
\hline Parameter & Influent & CF effluent & PF effluent \\
\hline $\mathrm{BOD}_{5}$ up to first harvest (Phase I)* & $42.4 \pm 4.7$ & $29.3 \pm 18.3$ & $23.5 \pm 3.6$ \\
\hline Removal efficiency (\%) & & 31.0 & 44.7 \\
\hline $\mathrm{BOD}_{5}$ up to second harvest (Phase II)* & $66.0 \pm 15.7$ & $40.3 \pm 12.7$ & $31.0 \pm 14.8$ \\
\hline Removal efficiency $(\%)$ & & 38.9 & 53.0 \\
\hline $\mathrm{NO}_{3}-\mathrm{N}$ up to first harvest (Phase I)* & $6.0 \pm 2.8$ & $3.1 \pm 0.4$ & $3.2 \pm 0.5$ \\
\hline Removal efficiency $(\%)$ & & 48.3 & 46.2 \\
\hline $\mathrm{NO}_{3}-\mathrm{N}$ up to second harvest (Phase II)* & $6.5 \pm 2.9$ & $4.9 \pm 2.4$ & $4.3 \pm 2.3$ \\
\hline Removal efficiency $(\%)$ & & 24.5 & 34.2 \\
\hline $\mathrm{NH}_{4}-\mathrm{N}$ up to first harvest (Phase I)* & $17.8 \pm 10.2$ & $14.8 \pm 9.2$ & $14.6 \pm 7.2$ \\
\hline Removal efficiency (\%) & & 16.6 & 18.1 \\
\hline \multicolumn{3}{|c|}{ Average removal of $\mathrm{N03}(\mathrm{mgl}-1)$ from first harvesting to second harvesting } & 4.30 \\
\hline Removal efficiency $(\%)$ & & & 34.18 \\
\hline $\mathrm{NH}_{4}-\mathrm{N}$ up to second harvest (Phase II)* & $9.9 \pm 4.0$ & $7.0 \pm 3.2$ & $6.9 \pm 3.6$ \\
\hline Removal efficiency $(\%)$ & & 29.4 & 30.1 \\
\hline
\end{tabular}

Concentration values are given as mean \pm standard deviation $\left(\mathrm{mg} \mathrm{L}^{-1}\right)$ - *Phase I: Jan-Jun 2006 and Phase II: JunSep 2006 
The average concentrations of $\mathrm{NO}_{3}-\mathrm{N}$ in the influent wastewater were $6.0 \pm 2.8$ and $6.5 \pm 2.9$ $\mathrm{mgL}^{-1}$ (Table 1) in Phase I and Phase II, respectively. In addition, the $\mathrm{NO}_{3}-\mathrm{N}$ concentration did not vary much during either phase. The $\mathrm{NO}_{3}-\mathrm{N}$ concentration was lower than that of the $\mathrm{NH}_{4}-\mathrm{N}$ concentrations $\left(9.9 \pm 4.0\right.$ to $\left.17.8 \pm 10.2 \mathrm{mgL}^{-1}\right)$. This result agrees with the report that wastewater generated from human waste can have significant levels of $\mathrm{NH}_{4}-\mathrm{N}$ and organic $\mathrm{N}$, but not a considerable amount of $\mathrm{NO}_{3}-\mathrm{N}$ (Huang et al., 2000).

Nitrogen removal is a combination of aerobic and anaerobic processes. Aerobic conditions are necessary for nitrification. Functioning of nitrifiers in the substrata of constructed wetlands are likely to be restricted to the surface layers of the medium and the root zone of wetland plants (Reddy and Patrick, 1984; Reddy et al., 1989). The high concentrations of $\mathrm{NH}_{4}-\mathrm{N}$ in the effluent indicate that nitrification was not limited by ammonium availability, but it may be limited by either the supply of oxygen to the substrate or the slow growth of nitrifiers in both phases in CF systems (Garcia et al., 2004).

While the PF system was expected to promote aerobic soil conditions during periods without application of water, the PF application in the present study showed improved $\mathrm{BOD}_{5}$ removal in both phases and higher $\mathrm{NO}_{3}-\mathrm{N}$ removal in the Phase II. The higher $\mathrm{BOD}_{5}$ removal suggested that $\mathrm{NH}_{4}-\mathrm{N}$ was produced by decomposition of organic matter in Phase II, which contributed to the higher $\mathrm{NH}_{4}-\mathrm{N}$ concentration in the effluent. In addition, a portion of the $\mathrm{NH}_{4}-\mathrm{N}$ may have been converted to $\mathrm{NO}_{2}-\mathrm{N}$ (not measured in lab due to unavailability of chemicals) and $\mathrm{NO}_{3}-\mathrm{N}$ through nitrification in the PF system. This may be supported by the fact that there was no significant $(\mathrm{P}<0.001)$ difference in ammonium removal between the two systems. A study (without drainage) carried out by Osorio and Garcia (2007) with intermittent (applying the corresponding volume of wastewater in $20 \mathrm{~min}$. per day) and continuous feeds, states, $98 \%$ ammonium removal was achieved with the intermittent system.

Better plant growth was observed in Phase II than in Phase I in the CF system. CF might have improved the $\mathrm{NH}_{4}-\mathrm{N}$ uptake and thereby increase the removal efficiency, but no significant difference between $\mathrm{CF}$ and $\mathrm{PF}$ applications was observed for $\mathrm{NH}_{4}$ removal during both phases. This may be due to a lag phase of microbial activity (Jamieson et al., 2003). The five-month period of the first phase and the three-month period of the second phase might not be long enough to improve the aeration of the media sufficiently to enhance the $\mathrm{NH}_{4}-\mathrm{N}$ removal. However, it seemed that these periods acted as lag periods only for $\mathrm{NH}_{4}-\mathrm{N}$. In contrast to $\mathrm{NH}_{4}-\mathrm{N}$ removal, $\mathrm{NO}_{3}-\mathrm{N}$ removal was increased during the second phase but did not show a significant difference between $\mathrm{CF}$ and PF systems.

\section{Plant growth}

The variations in shoot heights and shoot densities are presented in Fig. 1(A) and 1(B), respectively. The maximum heights of $S$. grossus during Phase I (the first 5 months) were $212 \pm 5$ and $212 \pm 8 \mathrm{~cm}$ for the CF and PF systems, respectively. The curves also show that the shoots reached their maximum height within 13 to 15 weeks after planting. There was no significant difference between the two systems in plant height during Phase I, but differences in the aboveground growth of plants became noticeable during Phase II. The growth of $S$. grossus was most rapid during this phase. The plants reached their maximum heights of 215 \pm 4 and $171 \pm 5 \mathrm{~cm}$ for $\mathrm{CF}$ and $\mathrm{PF}$ systems, respectively, between 8 to 10 weeks after planting. The final mean shoot densities were 89 and 52 shoots $\mathrm{m}^{-2}$ in the CF system and 50 and 31 shoots $\mathrm{m}^{-2}$ in the PF system during Phases I and II, respectively. The aboveground biomass gradually declined from 1.75 to 1.60 and 0.85 to $0.75 \mathrm{~kg} \mathrm{~m}^{-2}$ with distance from the 
inlet along the channel up to $16 \mathrm{~m}$ (Fig. 2) and showed a maximum of 1.9 and $1.2 \mathrm{~kg} \mathrm{~m}^{-2}$ near the outlet in both $\mathrm{CF}$ and PF systems.

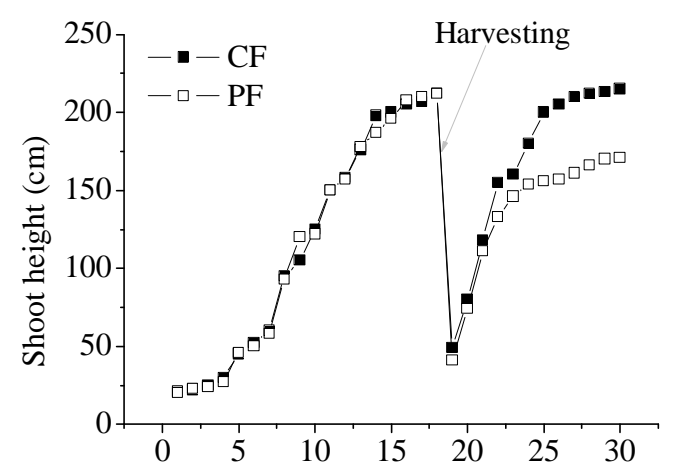

(a) Weeks after planting

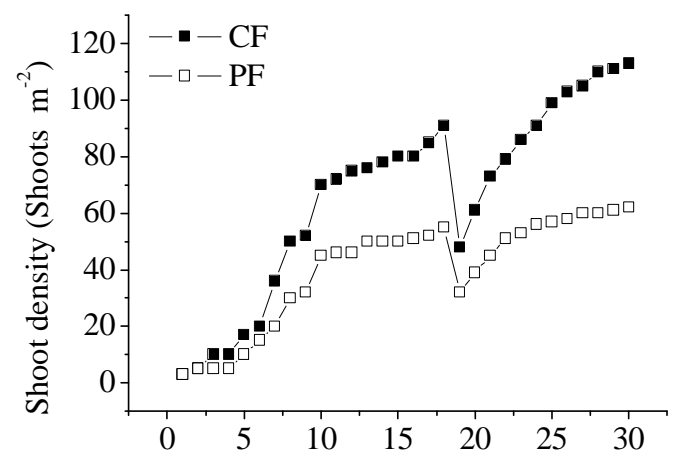

(b) Weeks after planting

Fig. 1. Plant growth under continuous feed (CF) and pulsed feed (PF) systems

(a) Mean cumulative shoot heights and (b) mean shoot densities of plants.

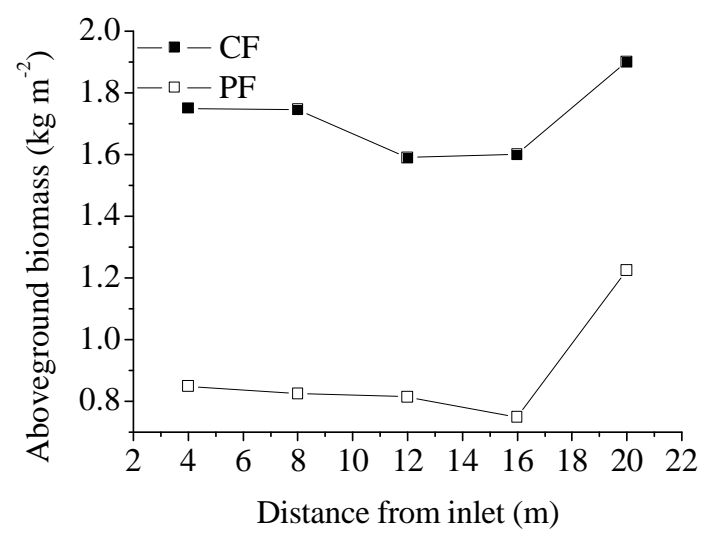

Fig. 2. Aboveground biomass distribution along the channel at the end of Phase 
A significant $(\mathrm{P}<0.001)$ decline in shoot densities was observed in the PF system during both phases. The reasons may be water stress and the disturbance between the root surface and the water film during the pulsing application. Pulsing might reduce the nutrient uptake and thereby reduce shoot density and plant biomass. A richer nutrient condition may enhance plant productivity (Tanner, 2001), and this would be revealed by the biomass variation along the channel. The maximum seasonal aboveground biomass for Scirpus spp. can range between 0.4 and $1.4 \mathrm{~kg} \mathrm{~m}^{-2}$ in temperate regions like North America (Tanner, 2001). The maximum aboveground biomasses for $S$. grossus in this study were 1.9 and $1.2 \mathrm{~kg} \mathrm{~m}^{-2}$ for CF and $\mathrm{PF}$ applications, respectively, during the first phase. Compared to the natural conditions, here the plants got rich nutrients and consequently showed higher biomasses.

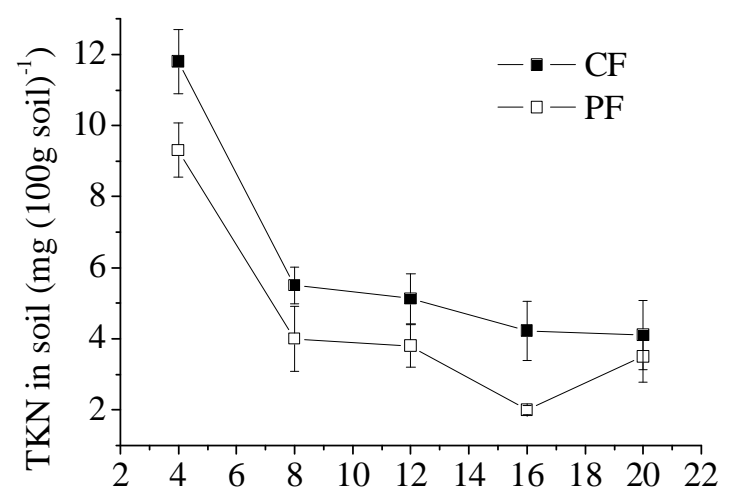

(a) Distance from inlet (m)

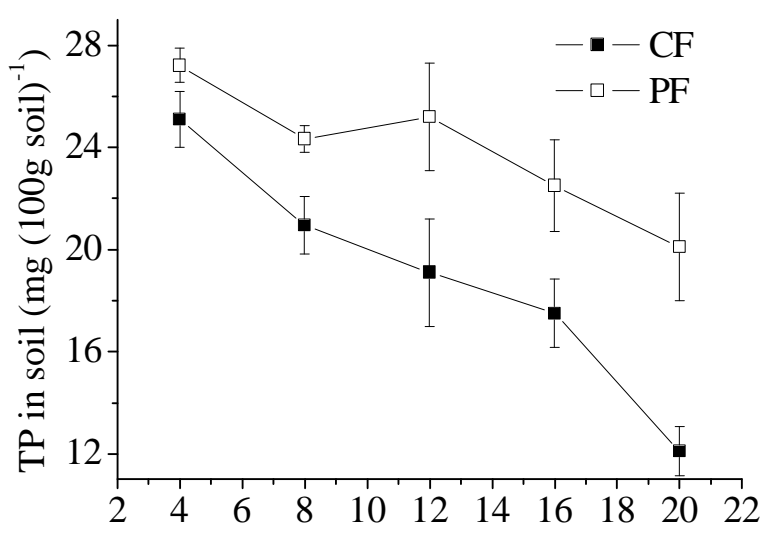

(b) Distance from inlet $(\mathrm{m})$

Fig. 3. Variations in (a) total Kjeldahl nitrogen (TKN) concentrations, and (b) total phosphorous (TP) concentration in soil along the channels of continuous feed $(\mathrm{CF})$ and pulsed feed (PF) systems. Concentrations are given as mean \pm standard deviation 


\section{TKN and TP in substrate}

The soil was tested at a depth of $10-20 \mathrm{~cm}$ below the soil surface, which is the root zone. The TKN and TP in the soil along the channels of the two systems were examined at the end of the study period (just before the second harvesting), and the values are presented in Figs. 3 (A) and (B). The highest concentrations of nitrogen (11.8 \pm 0.9 and $9.3 \pm 0.8 \mathrm{mg}$ per $100 \mathrm{~g}$ soil) were near the inlet, and the lowest $(4.1 \pm 1.0$ and $3.5 \pm 0.7 \mathrm{mg}$ per $100 \mathrm{~g}$ soil) were near the outlet in the $\mathrm{CF}$ and PF systems, respectively. The soil of the CF application system contained a comparatively higher concentration of available nitrogen than the soil of the PF application system. In contrast, higher available phosphorus concentrations were observed along the channel in the PF system than in the CF system. Compared with a previous study carried out by Jinadasa et al., (2005), the nitrogen values were low in the sediments in the current study. They have observed nearly $0.3 \%$ nitrogen in soil sediment, but no data was available on phosphorus.

A possible reason for the lower TKN in the soil of the PF system may be the physical agitation during the flow. In the PF unit, the wastewater flow $\left(56 \mathrm{~m}^{3}\right)$ was sent in over a period of five days, causing greater internal turbulence and mixing than in the CF system. The greater turbulence in the PF system allows a larger volume of water to pass through soil pores than in the CF system. A PF reaerates the surface of the soil. In addition, PF resulted in greater fluctuations of water depth than CF. These conditions might have improved the ammonium volatilization and thereby reduced the available soil nitrogen concentration in the PF system than in the CF system. In addition, both aerobic and anaerobic soil conditions are necessary for removal of nitrogen from wastewater. The discontinuous water application in the PF application creates temporal variations in the soil oxidation status (Poach et al., 2007). This PF application changes the soil oxidation condition along the channel as well as inside the substrate. As a result, alternately aerobic (which induces nitrification) and anaerobic (which induces denitrification) conditions may also have reduced the available nitrogen in the PF system.

The PF application had a significant effect on available phosphorus along the channel. The disturbance in the CF was smaller than in the PF system. This condition leads to better absorption of phosphorous by the roots of plants in the CF system. Therefore, the CF system showed a lower concentration of available phosphorous in the top layer. The different trends observed for nitrogen and phosphorus concentrations in the soil may be due to different removal mechanisms. Phosphorus removal is presumed to be mainly due to physical adsorption by the media and microbial activity, whereas nitrogen removal is mainly due to microbial processes (Reddy et al., 1989).

\section{CONCLUSIONS}

Pulse feeding in shallow free-water-surface in constructed wetlands is expected to provide greater oxidation compared to continuous feeding. Although the results obtained in this study under tropical conditions were dissimilar to previous studies in terms of ammonium removal, the pulse application of wastewater promoted the average $\mathrm{BOD}_{5}$ removal rate of $45-53 \%$ compared with the 31-39\% obtained in continuous flow system. Maximum $\mathrm{NO}_{3}-\mathrm{N}$ and $\mathrm{NH}_{4}-$ $\mathrm{N}$ removal was $48 \%$ and $30 \%$ in both units, and the two treatments did not show a statistically significant difference $(\mathrm{P}<0.001)$. The amounts of $\mathrm{N}$ were 11.8 and $9.3 \mathrm{mg}$ per $100 \mathrm{~g}$ soil and of $\mathrm{P}$ were 25.1 and $27.2 \mathrm{mg}$ per $100 \mathrm{~g}$ soil for the $\mathrm{CF}$ and PF systems, 
respectively. A notable reduction of plant biomass production was observed during the pulse flow application compared with the continuous flow system. The results also suggest that a pulse feeding of 5 days continuous wastewater application and 2 days without feeding may not be effective for ammonium removal in free water surface wetlands. In this research only a few fluctuation systems were investigated and compared the systems performances rather than optimizing the system performances. Therefore, towards the optimization concept different fluctuation frequencies are needed to be studied.

\section{REFERENCES}

APHA, AWWA and WEF. (1998). Standard methods for the examination of water and wastewater, $20^{\text {th }}$ Edition, American Public Health Association, American Water Works association and Environment Federation, Washington, D.C.

Clarke E, Baldwin and A. H. (2002). Responses of wetland plants to ammonia and water level. Ecolo. Engi.18: 257.

Garcia, J., Aguirre, P., Mujeriego, R., Huang, Y, Ortiz, L. and Bayona, J.M. (2004). Initial contaminant removal performance factors in horizontal flow reed beds used for treating urban wastewater. Water Res. 18: 1669-1678.

Garcia, J., Aguirre, P., Barragan, J., Mujeriego, R., Matamoros, V. and Bayona, J.M. (2005). Effect of key design parameters on the efficiency of horizontal subsurface flow constructed wetlands. Ecolo. Engi. 25: 405-418.

Headley, T.R., Herity, E. and Davison, L. (2005). Treatment at different depths and vertical mixing within a 1-m deep horizontal subsurface-flow wetland. Ecolo. Engi. 25: 567-582.

Huang, J., Reneau, R.B. Jr. and Hagedorn, C. (2000). Nitrogen removal in constructed wetlands employed to treat domestic wastewater. Water Res. 34: 2582-2588.

Jamieson, T.S., Stratton, G.W., Gordon, R. and Madani, A. (2003). The use of aeration to enhance ammonia nitrogen removal in constructed wetlands. Canadian Biosys. Engi. 45: 1.91.14 .

Jinadasa, K.B.S.N., Tanaka, N., Mowjood, M.I.M. and Werellagama, D.R.I.B. (2005). Effects on Vegetation on Pollutant Removal in a Constructed Wetland: Potential applications for Tropical Developing Countries. Proceedings IWA-ASPIRE., CD-ROM. Singapore.

Kadlec, R.H. (1995). Overview: Surface flow constructed wetlands. Water Sci. Tech. 32: 112.

Kadlec, R.H., Knight, R.L., Vymazal, J., Brix, H., Cooper, P. and Haberl, R. (2000). Constructed wetlands for pollution control. Processes, performance, design and operation, IWA Scientific and Technical Report No.8. IWA Specialist Group on Use of Macrophytes in Water Pollution Control. IWA Publishing, London, 155.

Merz, S.K. (2000). Guidelines for Using Free Water Surface Constructed Wetlands to Treat Municipal Sewage. Queensland Department of Natural Resources, 20-25. 
Osorio, A.C. and Garcia, J. (2007). Impact of different feeding strategies and plant presence on the performance of shallow horizontal subsurface-flow constructed wetlands. Sci. and Total Envir. 378: 253-262.

Pedrazzini, F.R., Tarsitano, R, (1986). Ammonia volatilization from flooded soil following urea application. Plant and Soil 91: 101-107.

Poach, M.E., Hunt, P.G., Reddy, G.B., Stone, K.C., Johnson, M.H. and Grubbs, A. (2007). Effect of intermittent drainage on swine wastewater treatment by marsh-pond-marsh constructed wetlands. Ecolo. Engi. 30: 43-50.

Reddy, K.R. and Patrick, W.H. (1984). Nitrogen transformations and loss in flooded soils and sediments. CRC. Crit. Rev. Env. Contr. 13: 273-309.

Reddy, K.R., Patrick, W.H., and Lindau, C.W. Jr. (1989). Nitrification-denitrification at the plant root-sediment interface in wetlands. Limnology and Oceanography 34: 1004-1013.

Systat Software Inc (2004). SigmaStat 3.1 for Windows. 501 Chanal Blvd, Suite E, Point Richmond CA, USA.

Tanner, C.C. (2001). Growth and nutrient dynamics of soft-stem bulrush in constructed wetlands treating nutrient rich wastewaters. Wetland Ecolo. and Mgt. 9: 49-73.

Wiessner, A., Kappelmeyer, U., Kunschk, P. and Kastner, M. (2005). Influence of the redox condition dynamic on the removal efficiency of a laboratory-scale constructed wetland. Water Res. 39: 248-256. 